\title{
Small Heat Shock Protein Responses Differ between Chaparral Shrubs from Contrasting Microclimates
}

\author{
Charles A. Knight \\ Department of Biological Sciences, California Polytechnic State University, San Luis Obispo, CA 93407, USA \\ Correspondence should be addressed to Charles A. Knight, knight@calpoly.edu
}

Received 26 February 2010; Accepted 30 August 2010

Academic Editor: Tadao Asami

Copyright () 2010 Charles A. Knight. This is an open access article distributed under the Creative Commons Attribution License, which permits unrestricted use, distribution, and reproduction in any medium, provided the original work is properly cited.

Small heat shock protein (sHsp) responses were studied for two evergreen perennial shrubs in the northern California chaparral; one common on warm, south-facing slopes (Ceanothus cuneatus), and the other on cooler, north-facing slopes (Prunus ilicifolia). Small Hsp expression was induced experimentally for field collected leaves. Leaf collections were made where the species co-occur. Small Hsp expression was quantified using two antibodies, one specific to a chloroplast $22 \mathrm{kD}$ sHsp and another that detects a broad range of sHsps. Differences between chloroplast sHsp accumulation, which protects thermally labile proteins in PSII, and the general sHsp response were examined. The species from the cooler microclimate, Prunus, had a lower induction temperature and accumulated greater levels of sHsps at low temperatures. Both Prunus and Ceanothus reached peak sHsp expression at $42^{\circ} \mathrm{C}$. The species from the warmer microclimate, Ceanothus, had greater sHsp expression at higher temperatures. Chloroplast sHsp expression generally tracked sHsp expression in Ceanothus, but in Prunus general Hsps were elevated before chloroplast sHsps. Variation between species for sHsp expression (induction temperatures, accumulation levels, and the duration of expression) coupled with the costs of Hsp synthesis, may contribute to differences in the abundance and distribution of plants across environmental gradients.

\section{Introduction}

There have been hundreds of biochemical studies of the heat shock protein (Hsp) response in plants (see $[1,2]$ for recent reviews), but previous studies have almost exclusively involved experimentally grown plants in controlled environments. Therefore, while our knowledge of the functional roles of Hsps has been rapidly expanding, there is still relatively little information concerning Hsp expression for plants growing in their natural environments. Of the few studies that have examined Hsp expression in the field, three made no report of Hsp expression in leaves [3-5], and the others examined Hsp expression agricultural fields $[6,7]$. In addition, a lack of comparative studies has precluded a general synthesis of how genetic differentiation for the Hsp response might contribute to adaptive evolution.

Leaf temperatures in the field can easily exceed those that lead to increased Hsp expression in artificial environments. Short duration temperature extremes $(\sim 15$ minutes $)$ can lead to increased Hsp expression [8]. Correlated abiotic stresses such as decreased water availability, high light, or low nutrients can also affect Hsp expression [9]. Plastic changes in protein synthesis, such as the Hsp response, may constitute a significant resource cost for plants, and significantly affect the distribution and abundance of species.

In plants, the functional roles of the small Hsps (sHsps) have received considerable attention. Small Hsps dominate protein synthesis during and after high temperature stress and can rapidly accumulate to greater than $1 \%$ of total leaf protein under some conditions [1,10-14]. While most eukaryotes have just a few sHsps, in plants the protein class has duplicated and diversified to include 20-50 nuclear encoded genes $[15,16]$. The evolutionary conservation of sHsps, combined with their diversification in plants, has led to the hypothesis that sHsps play an important role for whole plant thermal tolerance $[17,18]$.

This study was designed to address two questions. (1) How do induction temperatures and expression levels of 


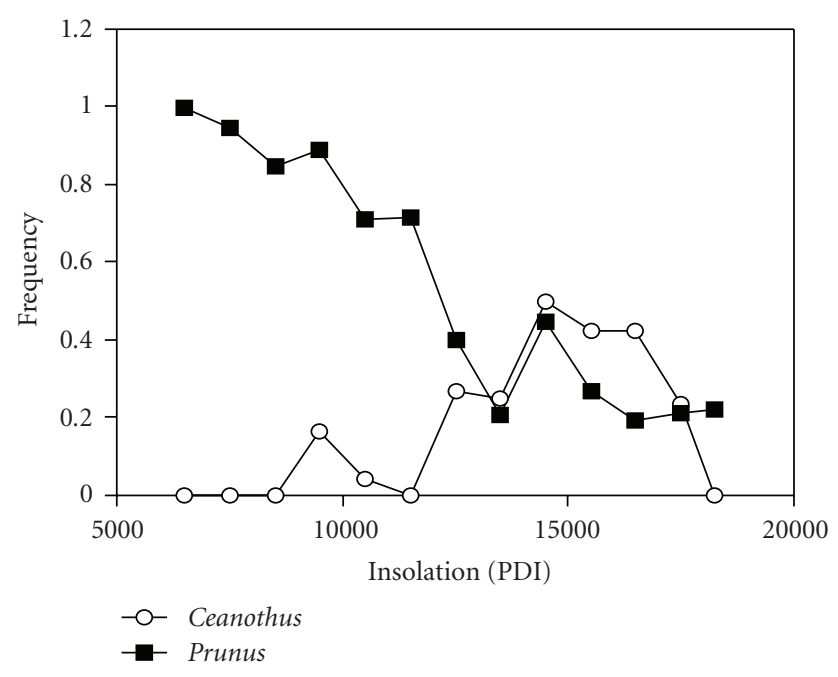

Figure 1: Microclimate distribution of Ceanothus cuneatus (open circles) and Prunus ilicifolia (closed circles). Potential diurnal insolation (PDI) was calculated using topographic position from an digital elevation model and a annual solar radiation model (figure reproduced from [19]).

sHsps differ between species with contrasting microclimate distributions? We addressed this questions using two evergreen perennial shrubs in the northern California chaparral; Ceanothus cuneatus codominant on warm, south-facing slopes, and Prunus ilicifolia a dominant species on cooler, north-facing slopes (Figure 1). Field leaf collections were made at sites where Ceanothus and Prunus cooccurred to control for other factors that could lead to variation in sHsp accumulation. The experiment was conducted using field collected leaf material to gain some realism for the natural context of sHsp expression at the expense of controlled environment assurances. (2) How does chloroplast sHsp expression track general sHsp expression? It is known that the chloroplast sHsp helps protect thermally labile proteins in PSII. Are chloroplast sHsps more or less temperature responsive compared to the general sHsp response?

\section{Materials and Methods}

Field work was conducted in the northern California chaparral at Jasper Ridge Biological Preserve (JRBP) on the campus of Stanford University. Ackerly et al. [19] quantified the microclimate distribution of shrub species at JRBP using line transects and vegetation plots combined with a solar insolation model. Ceanothus cuneatus is a codominant with Adenostoma fasciculatum on the high solar exposure southfacing slopes while Prunus ilicifolia is a codominant on the cooler north-facing slopes (Figure 1). Leaf temperatures for Prunus and Ceanothus were measured in the field using a Campbell Scientific data logger with two AM25T thermocouple multiplexers (Campbell Scientific, Logan, UT, USA). Twenty-five leaves of each species were measured at the microclimate extremes, and where the species cooccurred, by adhering 36 gauge type $\mathrm{E}$ thermocouples to the underside of leaves (Figure 4). One minute average leaf temperatures were recorded throughout the spring and summer.

2.1. Experimentally Induced sHsp Expression. The temperature dependence of sHsp expression was examined experimentally for field-collected leaves of Ceanothus and Prunus. Leaves with no visible sign of physiological stress were collected in March 2001 before they experienced significant naturally occurring heat stress. Leaf collections were made at sites where the species cooccurred to control for other factors that might influence sHsp expression. Three replicate groups of 15 leaves per species were subjected to a series of temperature treatments $\left(32,34,36,38,40,42,45^{\circ} \mathrm{C}\right)$ in air circulating chambers submerged in temperature-controlled water baths (Oven Industries, Mechanicsburg, PA, USA). We used detached leaves because it was the only method available to achieve precise and constant leaf temperatures for field collected leaves. Leaves were placed on top of a piece of moist filter paper inside the chamber to prevent drying. Leaf temperatures did not vary by more than $0.1^{\circ} \mathrm{C}$ (both between leaves and between set temperature and leaf temperature). Temperature treatments lasted $4 \mathrm{~h}$. Following the heat treatment, leaves were allowed to recover for $4 \mathrm{~h}$ under low light. They were then frozen in liquid $\mathrm{N}$ and stored at minus $80^{\circ} \mathrm{C}$ until protein extraction.

The photochemical efficiency of PSII was measured for a subset of leaves following the heat stresses using the ratio of variable to maximum fluorescence $\left(F_{v} / F_{m}\right) . F_{v} / F_{m}$ was measured after a 0.7 second saturating actinic light pulse of approximately $12,000 \mu \mathrm{mol} * \mathrm{~m}^{-2} * \mathrm{~s}^{-1}$ (Hansatech FMS2 fluorometer, King's Lynn, UK). Leaves were dark adapted for 30 min before $F_{v} / F_{m}$ measurements.

2.2. Protein Methods. The conserved nature of the Nterminal "methionine-rich" domain of the chloroplast sHsp allowed Downs et al. [18] to produce an antibody that detected chloroplast sHsps in heat-stressed plant tissue from a diverse assemblage of species representing five divisions of the plant kingdom. A similar strategy was used to design a polyclonal antibody that cross-reacts with many small heat shock proteins [20]. Heckathorn and Downs graciously provided these antibodies for this study.

Total soluble leaf protein was extracted using a ceramic mortar and pestle with an extraction buffer made from the following ingredients: $3 \% \mathrm{w} / \mathrm{v}$ SDS (sodium dodecyl sulfate), $10 \% \mathrm{v} / \mathrm{v} 1.5 \mathrm{M}$ Tris, $1 \% \mathrm{v} / \mathrm{v} 1 \mathrm{mM}$ PMSF (phenylmethylsulfonyl fluoride), $2 \% \mathrm{v} / \mathrm{v} 0.1 \mathrm{M}$ EDTA (ethylenediaminetetraacetic acid), $0.5 \% \mathrm{v} / \mathrm{v} 1 \mathrm{M} \varepsilon$-amino-n-caproic acid, $1 \%$ $\mathrm{v} / \mathrm{v} 1 \mathrm{M}$ benzamidine, $2 \% \mathrm{w} / \mathrm{v}$ PVP (polyvinylpyrrolidone), $4 \% \mathrm{w} / \mathrm{v}$ PVPP (polyvinylpolypyrrolidone), $0.1 \% \mathrm{w} / \mathrm{v}$ DTT (Dithiothreirtol), $0.2 \% \mathrm{w} / \mathrm{v}$ Ascorbate, and $0.1 \% \mathrm{v} / \mathrm{v}$ of the protease inhibitors antipain and leupeptin (modified from [9]). We found that the soluble protein concentration of the extract sample varies considerably with the ratio of extraction buffer to fresh weight of leaf tissue and with the duration of incubation, mixing and grinding with the extraction buffer. Therefore, for all samples we added $2 \mathrm{~mL}$ of the extraction buffer to 1 gram of fresh leaf material and continued grinding the leaf tissue in the mortar and pestle 
for 10 minutes after pulverizing the leaf tissue on liquid N. Samples were boiled for $4 \mathrm{~min}$, centrifuged for $15 \mathrm{~min}$ at 15,000 revolutions per min, and the supernatant was collected and stored at $-80^{\circ} \mathrm{C}$.

The soluble protein concentration of the extract was determined using a Coomasie dot blot on Whatman filter paper (\#4) and quantified using a Hewlett Packard ScanJet II laser scanner (Palo Alto, California, USA, after [21, 22]). Sample concentrations were inferred from a standard curve of BSA serial dilutions of known concentration. $40 \mathrm{ug}$ of soluble protein was loaded on a precast $5 \%-20 \%$ TRISglycine SDS-PAGE gels (BIO-RAD, Hercules, California, USA). A positive control was run on each gel to account for blot-to-blot variation. Following separation, proteins were transferred to a PVDF (polyvinylidene difluoride) membrane by Western Blot. Membranes were blocked for $2 \mathrm{~h}$ following transfer in a Tris/powdered milk solution. The optimal antibody concentrations were found by serial dilution so that resulting band intensities were within the linear range of detection. The PVDF membranes were incubated overnight at room temperature with a $1 / 3000$ dilution of the polyclonal sHsp antibody (obtained from a generous gift from Heckathorn), or a 1/5000 dilution of the chloroplast sHsp antibody, both of which were followed by a $1.5 \mathrm{~h}$ incubation with a alkaline phosphatase conjugated secondary antibody (Sigma, St. Louis, Missouri, USA; 1/10000 dilution). Accumulation levels of sHsps were quantified using a Hewlett Packard ScanJet II and Scion Image for Windows image analysis software (available free at http://www.scioncorp.com/), following development with the alkaline phosphatase substrate. sHsp accumulation levels are expressed as a percentage of the positive control.

\section{Results}

3.1. Differences between Species for sHsp Expression. There was a significant difference between Prunus and Ceanothus for the temperature dependent accumulation of sHsps (Figure 2). There was a significant difference for general sHsp expression, (ANOVA, $F=6.21, P=.01$, Figure $2(\mathrm{a})$ ), and chloroplast sHsp expression (ANOVA, $F=5.32, P=.01$, Figure 2(b)). At low temperatures Prunus, which is common on the cooler north-facing slopes, had greater levels of general sHsp expression as well as for the chloroplast sHsp (Figures 2(a) and 2(b)). Both species exhibited peak general sHsp expression after the $42^{\circ} \mathrm{C}$ treatment. Chloroplasts sHsp expression peaked at $40^{\circ} \mathrm{C}$ for Prunus and at $42^{\circ} \mathrm{C}$ in Ceanothus. After the $32^{\circ} \mathrm{C}$ treatment low levels of sHsps were expressed for Prunus, while only trace amounts were present for Ceanothus. Neither species expressed chloroplast sHsps following the $32^{\circ} \mathrm{C}$ treatment. Both Prunus and Ceanothus expressed general sHsps after the $45^{\circ} \mathrm{C}$ temperature treatment. Chloroplast sHsp expression was significantly reduced following the $45^{\circ} \mathrm{C}$ treatment in Prunus while only somewhat reduced in Ceanothus.

Photosynthetic thermal tolerance, measured by the fluorescence parameter $F_{v} / F_{m}$, was significantly different between species (ANOVA $F=4.68, P=.05$, Figure 2(c)). Ceanothus had greater at $F_{v} / F_{m}$ higher temperatures

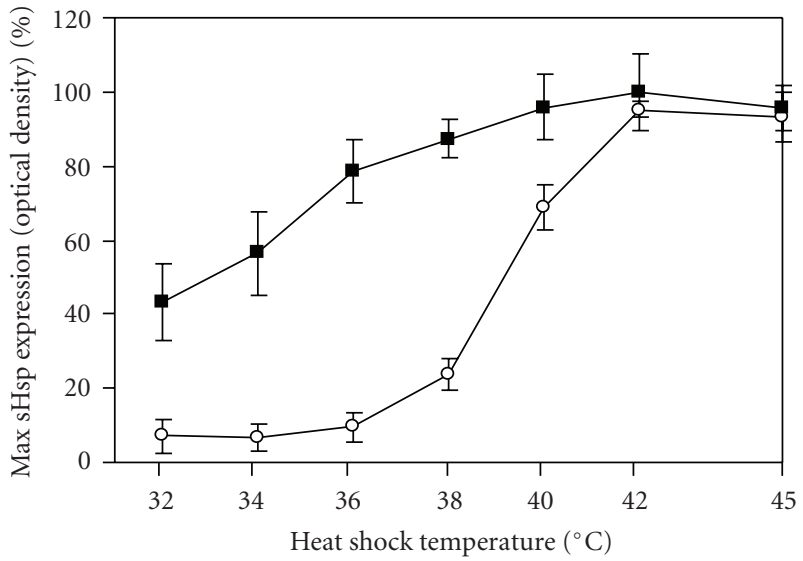

(a)

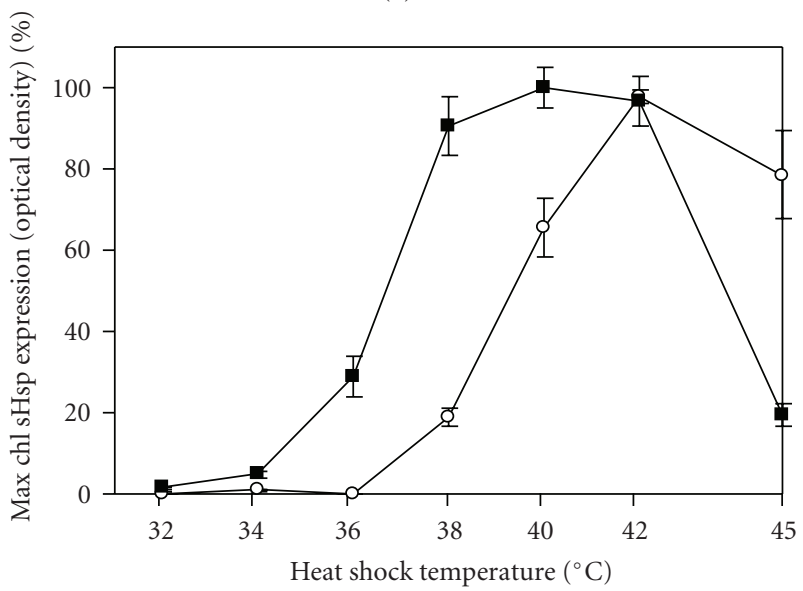

(b)

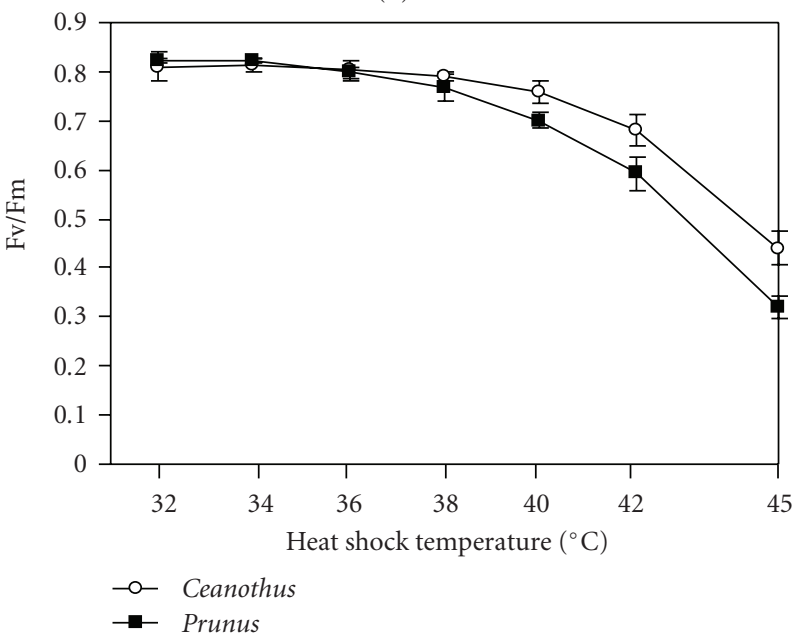

(c)

Figure 2: (a) The temperature-dependent decline for $F_{v} / F_{m}$ following temperature treatments in Ceanothus and Prunus. General sHsp responses (b) and chloroplast sHsp expression following the same temperature treatments as (a) In (a), (b), and (c) Prunus is represented with a solid square and Ceanothus an open circle.

$\left(36^{\circ} \mathrm{C}+\right)$. At low temperatures there was a positive correlation between $F_{v} / F_{m}$ and sHsp expression, but at high temperatures the relationship became negative. 


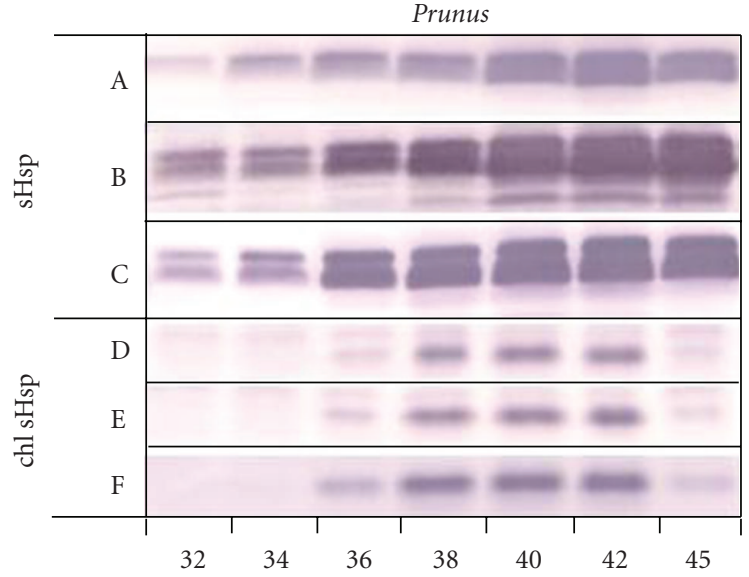

(a)

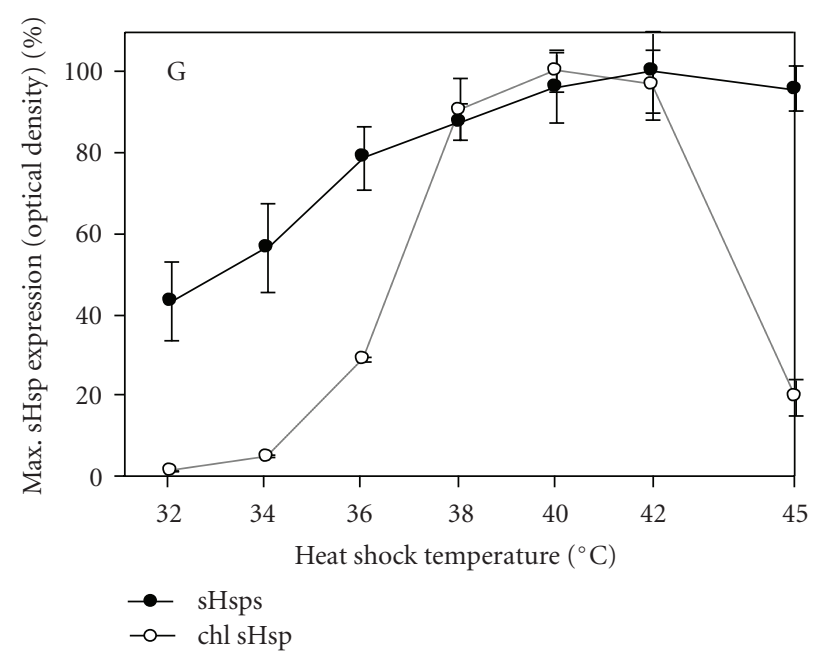

(c)

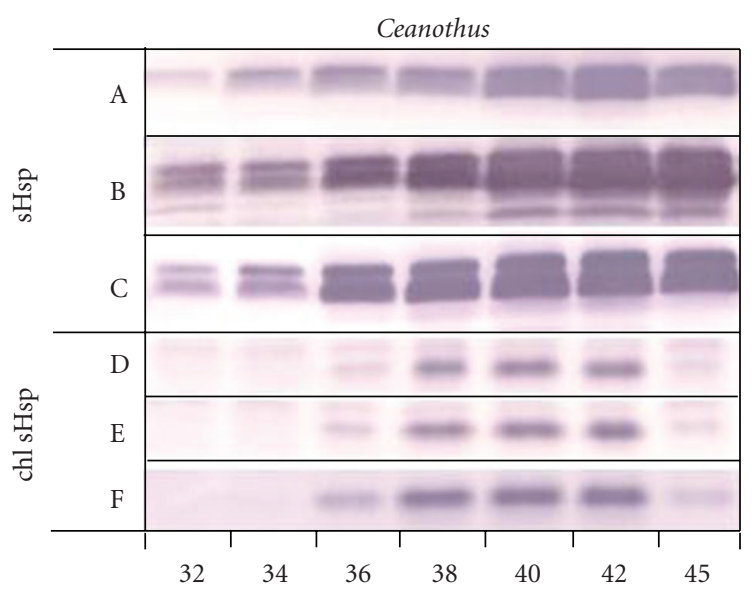

(b)

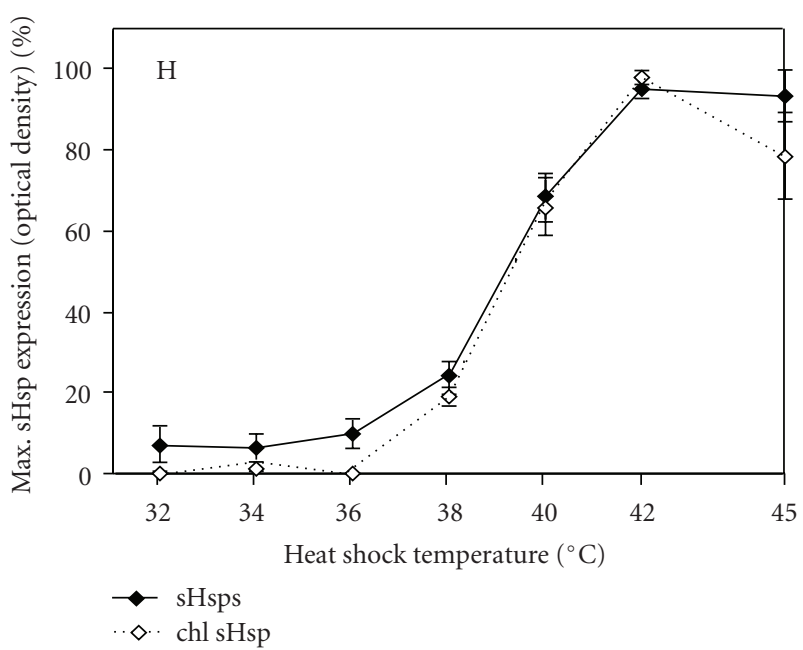

(d)

Figure 3: Experimentally induced sHsp expression for Ceanothus and Prunus after a series of temperature treatments $\left(32\right.$ to $42^{\circ} \mathrm{C}$ on $2^{\circ} \mathrm{C}$ intervals and $45^{\circ} \mathrm{C}$ ). Panels $\mathrm{A}, \mathrm{B}$, and $\mathrm{C}$ are western blots of the three replicates using the general sHsp antibody. Panels $\mathrm{D}$, E, and $\mathrm{F}$ are western blots of the three replicates using the chloroplast sHsp (chl. sHsp) antibody. Panels $\mathrm{G}$, and $\mathrm{H}$ are the optical quantification of the three replicates. Error bars are SE for the three replicates.

3.2. Differences between the Chloroplast and General sHsp Response. Chloroplast sHsp expression generally tracked general sHsp accumulation in Ceanothus, except following the $45^{\circ} \mathrm{C}$ treatment, when chloroplast sHsp expression was slightly reduced compared to general sHsp expression (Figure $3 \mathrm{H}$ ). In Prunus, general sHsps were expressed at lower temperatures compared to chloroplast sHsps (Figure $3 \mathrm{G}$ ), and the chloroplast sHsp was significantly down regulated following the $45^{\circ} \mathrm{C}$ temperature treatment compared to the general sHsps response.

3.3. Leaf Temperature Variation. Where the species cooccurred (where leaf collections were made for this study) leaf temperatures were not significantly different between Ceanothus and Prunus (ANOVA, $F=6.13, P=.01$ ). However, leaf temperatures varied considerably where the species are most common in the field (i.e., at opposite extremes of the microclimate gradient at our field site,
Figure 4). Leaf temperatures for Ceanothus on the warmer south facing slope exceeded $32^{\circ} \mathrm{C}$ on most days, while temperatures were rarely that hot for Prunus on the cooler north facing slope. On most days leaf temperatures differed by more than $10^{\circ} \mathrm{C}$ between Prunus and Ceanothus at these microclimate extremes. Solar radiation is the primary factor that establishes these microclimate differences. Figure 4 shows six days of leaf temperature measurements. When solar radiation was variable, microclimate leaf temperature differences were not as great (see the second day in Figure 2).

\section{Discussion}

We observed significant differences for sHsp accumulation between chaparral shrubs with contrasting microclimate affinities. Prunus illicitifolia, which is common on cooler north-facing slopes (Figures 1 and 4) had greater sHsp expression at lower temperatures compared to Ceanothus 


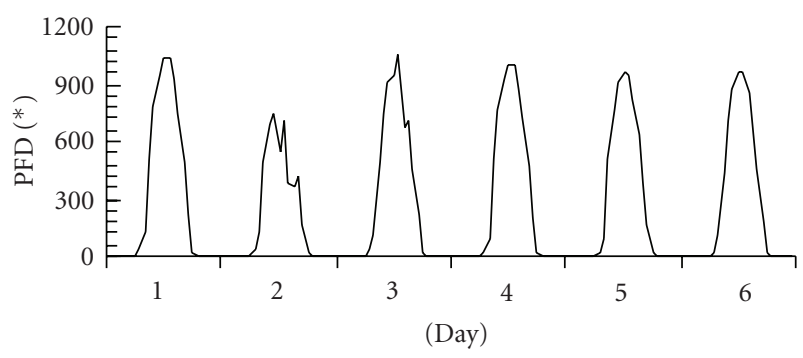

(a)

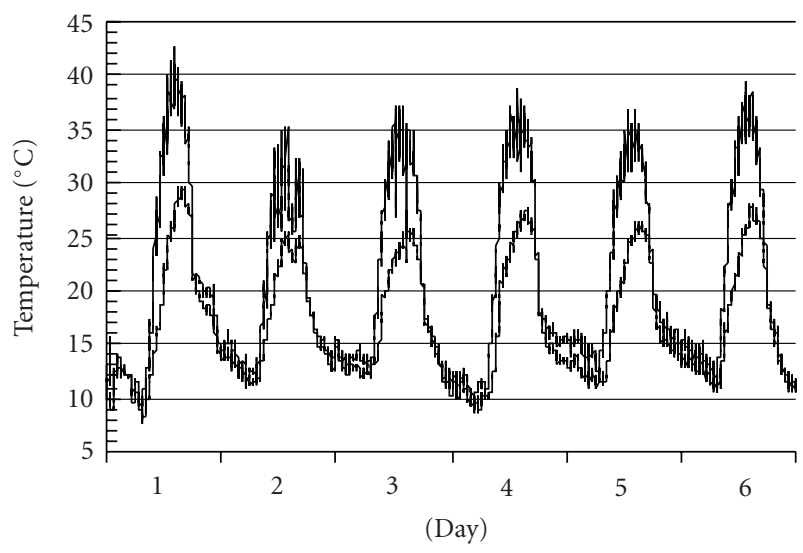

(b)

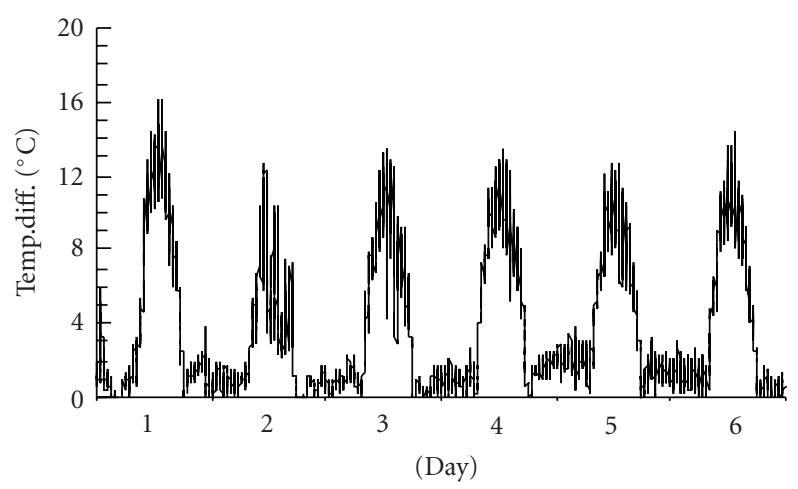

(c)

Figure 4: (a) Daily time course of photon flux density (PFD), (b) leaf temperature on north and south facing slopes (leaf temperatures were warmer on the south facing slope), and (c) the leaf temperature difference between the two microclimates. The leaf temperature measurements were the average of 25 sun leaves for each microclimate.

cuneatus, an abundant species on warmer south-facing slopes. Prunus also had lower photosynthetic thermal tolerance (Figure 2(c)) and a reduced capacity to synthesize sHsps at high temperatures. Knight and Ackerly [8] documented a similar pattern in Encelia for comparisons between Encelia farinosa, a species abundant in the Mojave desert, and Encelia californica, a species common on the cooler coastal bluffs of southern California.

In a review article of photosynthetic thermal tolerance based on gas exchange and fluorescence studies, Berry and
Bjorkman [23] suggested that $42^{\circ} \mathrm{C}$ is a critical thermal breakpoint for photosynthetic performance. Both Ceanothus and Prunus reached peak sHsp expression after 4 hours $42^{\circ} \mathrm{C}$ temperature treatments. The Encelia species studied by Knight and Ackerly [8] also reached peak sHsp expression at $42^{\circ} \mathrm{C}$ after similar temperature treatments. These observations reinforce Berry and Bjorkman's suggestion that $42^{\circ} \mathrm{C}$ is a critical thermal threshold for plants.

Increased sHsp expression may constitute a significant resource cost for plants and contribute to differences in the distribution and abundance of species across microclimate gradients. Leaf temperature measurements where Prunus is abundant indicated that it rarely experiences leaf temperatures in the field that lead to significant increases in sHsp expression (based on our experimental measurements of sHsp expression). However, Ceanothus, growing on the hot, south-facing slopes, frequently exceeded leaf temperatures that induced sHsp expression in our experiment. Conservative allocation strategies involving long leaf lifespan, high leaf nitrogen content, and reduced maximal photosynthetic performance [24] may help sustain sHsp expression for plants growing in thermally stressful habitats.

Variation in the sHsp response between species and artificially selected crop genotypes has previously been correlated with whole plant thermotolerance [25-31]. However, most of these studies measured Hsp expression after a single temperature. For example, Downs et al. [18] sampled a broad taxonomic group and found that most species synthesized the chloroplast $\mathrm{sH}$ sp following a $40^{\circ} \mathrm{C}$ heat stress, and species from warmer climates accumulated greater concentrations of chloroplast sHsp than species from cooler climates. However, Knight and Ackerly [32] found no correlation between expression levels of the chloroplast Hsp following $45^{\circ} \mathrm{C}$ temperature treatments and mean environmental conditions within the geographic ranges of eight species of Ceanothus. Comparisons of sHsp induction temperatures gleaned from full temperature-dependent induction profiles may provide more reliable comparisons between species than single temperature comparisons.

Accumulating evidence suggests that both the chloroplast and mitochondrial sHsps are important for the maintenance of photosynthetic and respiratory electron transport during and after high temperature stress. Heckathorn et al. [31] added purified chloroplast sHsp to isolated chloroplasts both before and after heat treatments and demonstrated that the chloroplast sHsp protects PSII oxygen evolution. In another study, Downs and Heckathorn [20] demonstrated functional inactivation of the mitochondrial sHsp, by protein-specific antibodies, leads to decreased levels of oxidative phosphorylation in isolated mitochondria, and that addition of purified mitochondrial sHsps to preheat stressed mitochondria leads to increased levels of oxidative phosphorylation. Both the chloroplast and mitochondrial sHsp are nuclear encoded and therefore the isolated organelles in the previous studies could not synthesize the sHsps denovo. In addition, MiyaoTokutomi et al. [33] demonstrated that constitutive expression of the chloroplast sHsp in transgenic tobacco plants leads to increased PSII thermotolerance. 
In our study, chloroplast sHsp expression tracked general sHsp expression in Ceanothus, with the exception that following the $45^{\circ} \mathrm{C}$ temperature treatment the chloroplast sHsp expression was somewhat reduced compared to general sHsp expression. However, in Prunus, chloroplast sHsp expression was not induced until higher temperatures, and was also significantly reduced following the $45^{\circ} \mathrm{C}$ treatment. Given that previous investigators have shown that the $22 \mathrm{kD}$ chloroplast sHsp protects thermally labile proteins of PSII it is surprising that the chloroplast sHsp is not upregulated until higher temperatures compared to the general sHsp response. The temperature-dependent induction of chloroplast sHsps was quite similar between the two species. Perhaps this similarity is due to the conserved nature of the proteins involved in the C3 photosynthetic apparatus. Differences between species for the general sHsp response may be more informative if these proteins protect more derived proteins perhaps uniquely adapted in thermally sensitive species.

The symptomatic and protective roles of sHsps lead to conflicting hypotheses concerning the correlation between sHsp expression and whole plant or photosynthetic thermotolerance. The evolution of thermotolerance may partly involve the evolution of greater individual protein thermostability $[34,35]$. Such possibilities may partly explain why some studies have demonstrated a positive relationship between HSP expression and plant thermotolerance $[18,25$, $26,30,36,37$ ], while several other studies have observed no relationship [13, 29, 32, 38].

The results for sHsp expression presented here rely on immunological assays using antibodies constructed against consensus regions of the methionine-rich chloroplast sHsp and for the "small heat shock domain" common to all sHsps $[15,16]$. The method is limited by the fact that differences in antigenicity of our antibodies between species may have contributed to contrasting results between species. However, Downs et al. [18] was able to detect the chloroplast sHsp expression in a diverse assemblage of plant species using the same antibody used here. While differences between species for sHsp expression at any particular temperature may be difficult to infer due to antigenicity effects, general trends for induction temperatures, peak accumulation temperatures, or thermal maxima for Hsp expression may still be reliable comparisons. Variation in antigenicity may be less of a problem for the general sHsp antibody which may detect many of the 30-60 different sHsps.

Several questions concerning the evolution and functional significance of Hsp expression merit further attention. For instance, does evolution in thermally stressful environments involve natural selection favoring more thermally stabile proteins [35], or better mechanisms for maintaining proteins in their folding competent states (e.g., Hsps)? Understanding the importance of these alternative strategies will aid in interpreting variation in induction temperature or expression levels of Hsps between species. Comparative studies involving species from contrasting environments are critical for understanding the adaptive and functional significance of Hsp expression. Research on relative costs and benefits of Hsp expression is also needed to better understand selection pressures influencing the Hsp response.
It is also possible that the altered Hsp expression profiles that we observed are the result of differential evolutionary histories. For example, members of the genus Prunus are more typically found in cooler environments, and therefore, the Prunus ilicifolia that we studied here may have had different Hsp induction profiles as a result of this evolutionary history.

\section{Abbreviations}

sHsp: Small heat shock protein

$F_{v} / F_{m}$ : Variable to maximal fluorescence

PSII: Photosystem II.

\section{Acknowledgments}

Many thanks to Kathleen Brizgys for help with field collections, Radika Bhaskar for help with protein extraction and quantification, Scott Heckathorn, Jim Coleman, and Craig Downs for assistance with protein methods and for providing the chloroplast and general sHsp antibodies. The paper was supported in part from a Tri-Agency (DOE, NSF, USDA) Training Grant in Plant Biology an NSF Dissertation Improvement Grant (IBN-9902295), a Jasper Ridge-Mellon Foundation Research Support grant, and a fellowship from the Center for Evolutionary Studies at Stanford University.

\section{References}

[1] E. Vierling, "The roles of heat shock proteins in plants," Annual Review of Plant Physiology and Plant Molecular Biology, vol. 42, no. 1, pp. 579-620, 1991.

[2] M. E. Feder and G. E. Hofmann, "Heat-shock proteins, molecular chaperones, and the stress response: evolutionary and ecological physiology," Annual Review of Physiology, vol. 61, pp. 243-282, 1999.

[3] L. D. Hernandez and E. Vierling, "Expression of low molecular weight heat-shock proteins under field conditions," Plant Physiology, vol. 101, no. 4, pp. 1209-1216, 1993.

[4] R. G. Stout, M. L. Summers, T. Kerstetter, and T. R. McDermott, "Heat- and acid-tolerance of a grass commonly found in geothermal areas within Yellowstone National Park," Plant Science, vol. 130, no. 1, pp. 1-9, 1997.

[5] T. S. Al-Niemi and R. G. Stout, "Heat-shock protein expression in a perennial grass commonly associated with active geothermal areas in western North America," Journal of Thermal Biology, vol. 27, no. 6, pp. 547-553, 2002.

[6] J. J. Burke, J. L. Hatfield, R. R. Klein, and J. E. Mullet, "Accumulation of heat shock proteins in field-grown cotton (Gossypium hirsutum)," Plant Physiology, vol. 78, no. 2, pp. 394-398, 1985.

[7] J. A. Kimpel and J. L. Key, "Heat shock in plants," Trends in Biochemical Sciences, vol. 10, no. 9, pp. 353-357, 1985.

[8] C. A. Knight and D. D. Ackerly, "Small heat shock protein responses of a closely related pair of desert and coastal Encelia," International Journal of Plant Sciences, vol. 164, no. 1, pp. 53-60, 2003.

[9] S. A. Heckathorn, G. J. Poeller, J. S. Coleman, and R. L. Hallberg, "Nitrogen availability and vegetative development influence the response of ribulose 1,5-bisphosphate carboxylase/oxygenase, phosphoenolpyruvate carboxylase, and heat-shock protein content to heat stress in Zea mays L," 
International Journal of Plant Sciences, vol. 157, no. 5, pp. 546$553,1996$.

[10] A. E. Derocher, K. W. Helm, L. M. Lauzon, and E. Vierling, "Expression of a conserved family of cytoplasmic low molecular weight heat shock proteins during heat stress and recovery," Plant Physiology, vol. 96, no. 4, pp. 1038-1047, 1991.

[11] M.-H. Hsieh, J.-T. Chen, T.-L. Jinn, Y.-M. Chen, and C.-Y. Lin, "A class of soybean low molecular weight heat shock proteins: immunological study and quantitation," Plant Physiology, vol. 99, no. 4, pp. 1279-1284, 1992.

[12] C. J. Howarth and H. J. Ougham, "Tansley review no. 51: gene expression under temperature stress," New Phytologist, vol. 125, pp. 1-26, 1993.

[13] M. A. O'Connell, "Heat shock proteins and thermotolerance," in Stress-Induced Gene Expression in Plants, A. S. Basra, Ed., pp. 163-183, Harwood, Chur, Switzerland, 1994.

[14] A. P. Arrigo and J. Landry, "Expression and function of the low-molecular-weight heat shock proteins," Cold Spring Harbor Monograph Series, vol. 26, pp. 335-373, 1994.

[15] E. R. Waters, "The molecular evolution of the small heat-shock proteins in plants," Genetics, vol. 141, no. 2, pp. 785-795, 1995.

[16] E. R. Waters, G. J. Lee, and E. Vierling, "Evolution, structure and function of the small heat shock proteins in plants," Journal of Experimental Botany, vol. 47, no. 296, pp. 325-338, 1996.

[17] J. S. Coleman, S. A. Heckathorn, and R. L. Hallberg, "Heatshock proteins and thermotolerance: linking molecular and ecological perspectives," Trends in Ecology and Evolution, vol. 10, no. 8, pp. 305-306, 1995.

[18] C. A. Downs, S. A. Heckathorn, J. K. Bryan, and J. S. Coleman, "The methionine-rich low-molecular-weight chloroplast heat-shock protein: evolutionary conservation and accumulation in relation to thermotolerance," American Journal of Botany, vol. 85, no. 2, pp. 175-183, 1998.

[19] D. D. Ackerly, C. A. Knight, S. B. Weiss, K. Barton, and K. P. Starmer, "Leaf size, specific leaf area and microhabitat distribution of chaparral woody plants: contrasting patterns in species level and community level analyses," Oecologia, vol. 130, no. 3, pp. 449-457, 2002.

[20] C. A. Downs and S. A. Heckathorn, "The mitochondrial small heat-shock protein protects $\mathrm{NADH}$ : ubiquinone oxidoreductase of the electron transport chain during heat stress in plants," FEBS Letters, vol. 430, no. 3, pp. 246-250, 1998.

[21] S. Ghosh, S. Gepstein, J. J. Heikkila, and E. B. Dumbroff, "Use of scanning densitometer or an ELISA plate reader for measurement of nanogram amounts of protein in crude extracts from biological tissues," Analytical Biochemistry, vol. 169, no. 2, pp. 227-233, 1988.

[22] S. G. Vincent, P. R. Cunningham, N. L. Stephens, A. J. Halayko, and J. T. Fisher, "Quantitative densitometry of proteins stained with coomassie blue using a Hewlett Packard Scanjet scanner and Scanplot software," Electrophoresis, vol. 18, no. 1, pp. 6771, 1997.

[23] J. A. Berry and O. Bjorkman, "Photosynthetic response and adaptation to high temperature in plants," Annual Review of Plant Physiology, vol. 31, pp. 491-543, 1980.

[24] P. B. Reich, M. B. Walters, and D. S. Ellsworth, "From tropics to tundra: global convergence in plant functioning," Proceedings of the National Academy of Sciences of the United States of America, vol. 94, no. 25, pp. 13730-13734, 1997.

[25] H. J. Ougham and J. L. Stoddart, "Synthesis of heat-shock protein and acquisition of thermotolerance in high-temperature tolerant and high-temperature susceptible lines of Sorghum bicolor," Plant Science, vol. 44, no. 3, pp. 163-167, 1986.
[26] M. Krishman, H. T. Nguyen, and J. J. Burke, "Heat shock protein synthesis and thermal tolerance in wheat," Plant Physiology, vol. 90, pp. 140-145, 1989.

[27] S. J. Colomobo, M. L. Colclough, V. R. Timmer, and E. Blumwald, "Clonal variation in heat tolerance and heat shock protein expression in black spruce," Silvae Genetica, vol. 41, pp. 234-239, 1992.

[28] J. Weng and H. T. Nguyen, "Expression of a conserved family of cytoplasmic low molecular weight heat shock proteins during heat stress and recovery," Theoretical and Applied Genetics, vol. 84, pp. 941-946, 1992.

[29] C. Frova and M. S. Gorla, "Quantitative expression of maize HSPs: genetic dissection and association with thermotolerance," Theoretical and Applied Genetics, vol. 86, no. 2-3, pp. 213-220, 1993.

[30] S.-Y. Park, R. Shivaji, J. V. Krans, and D. S. Luthe, "Heat-shock response in heat-tolerant and nontolerant variants of Agrostis palustris Huds," Plant Physiology, vol. 111, no. 2, pp. 515-524, 1996.

[31] S. A. Heckathorn, C. A. Downs, and J. S. Coleman, "Small heat shock proteins protect electron transport in chloroplasts and mitochondria during stress," American Zoologist, vol. 39, no. 6, pp. 865-876, 1999.

[32] C. A. Knight and D. D. Ackerly, "Correlated evolution of chloroplast heat shock protein expression in closely related plant species," American Journal of Botany, vol. 88, no. 3, pp. 411-418, 2001.

[33] M. Miyao-Tokutomi, B. H. Lee, N. Mizusawa, and N. Yamamoto, "Active oxygen and photoinhibition of photosystem II," in Proceedings of the 11th International Congress on Photosynthesis, pp. 2097-2102, Kluwer Academic Press, The Netherlands, 1998.

[34] P. W. Hochachka and G. N. Somero, Biochemical Adaptation, Princeton University Press, Princeton, NJ, USA, 1984.

[35] R. Sterner and W. Liebl, "Thermophilic adaptation of proteins," Critical Reviews in Biochemistry and Molecular Biology, vol. 36, no. 1, pp. 39-106, 2001.

[36] Z. Ristic, G. Yang, B. Martin, and S. Fullerton, "Evidence of association between specific heat-shock protein(s) and the drought and heat tolerance phenotype in maize," Journal of Plant Physiology, vol. 153, no. 3-4, pp. 497-505, 1998.

[37] C. P. Joshi, N. Y. Klueva, K. J. Morrow, and H. T. Nguyen, "Expression of a unique plastid-localized heat-shock protein is genetically linked to acquired thermotolerance in wheat," Theoretical and Applied Genetics, vol. 95, no. 5-6, pp. 834-841, 1997.

[38] S. E. Fender and M. A. O'Connell, "Heat shock protein expression in thermotolerant and thermosensitive lines of cotton," Plant Cell Reports, vol. 8, no. 1, pp. 37-40, 1989. 

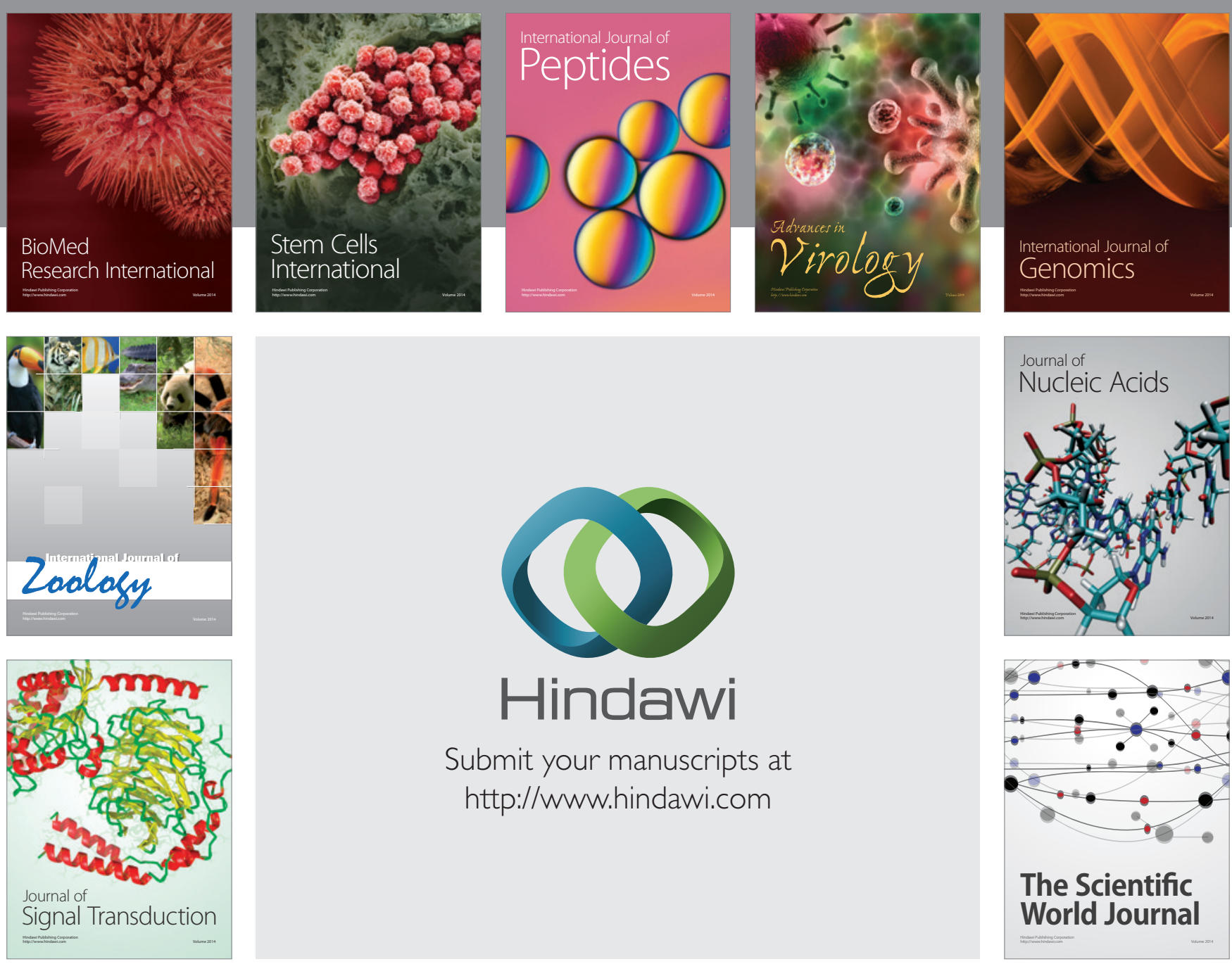

Submit your manuscripts at

http://www.hindawi.com
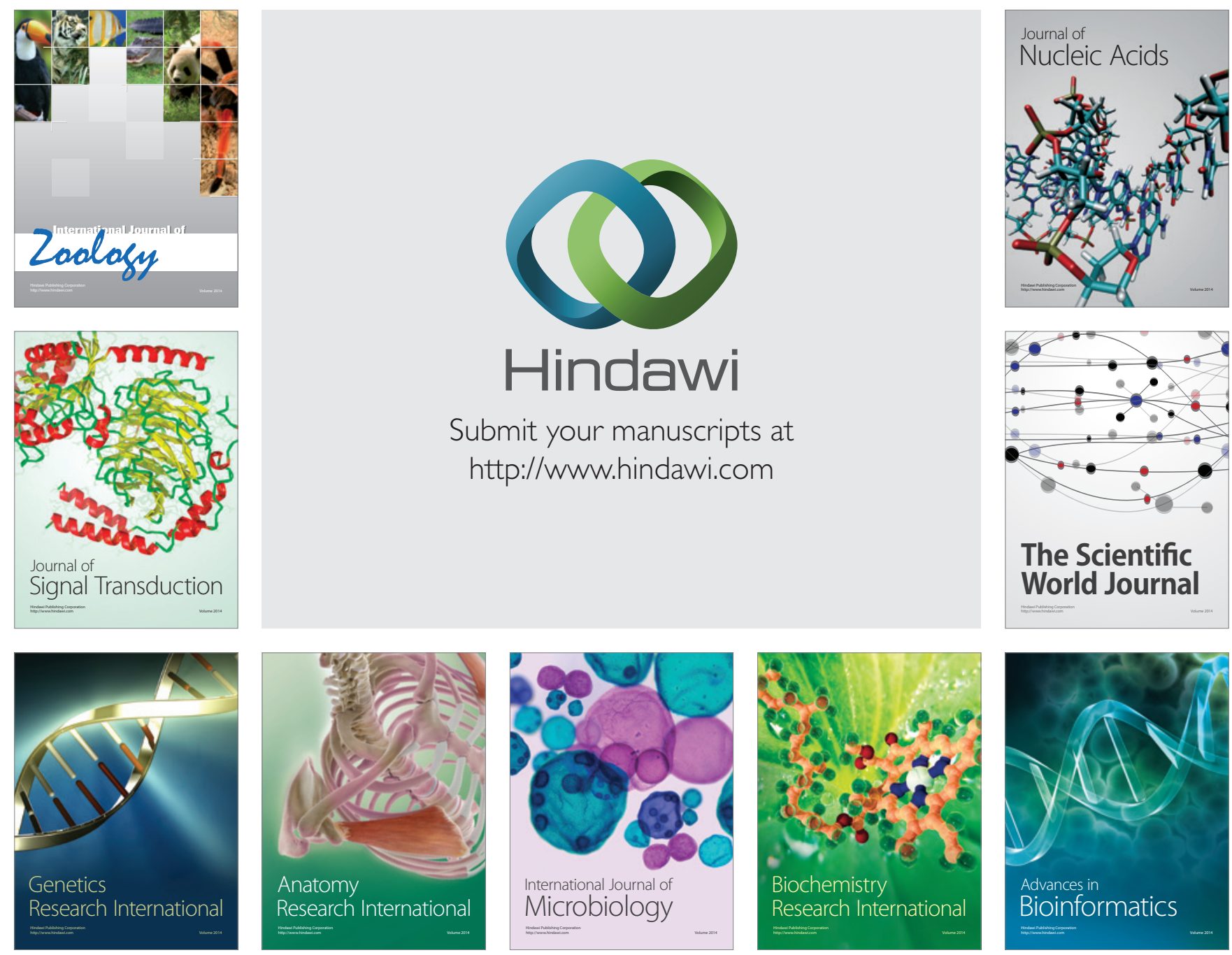

The Scientific World Journal
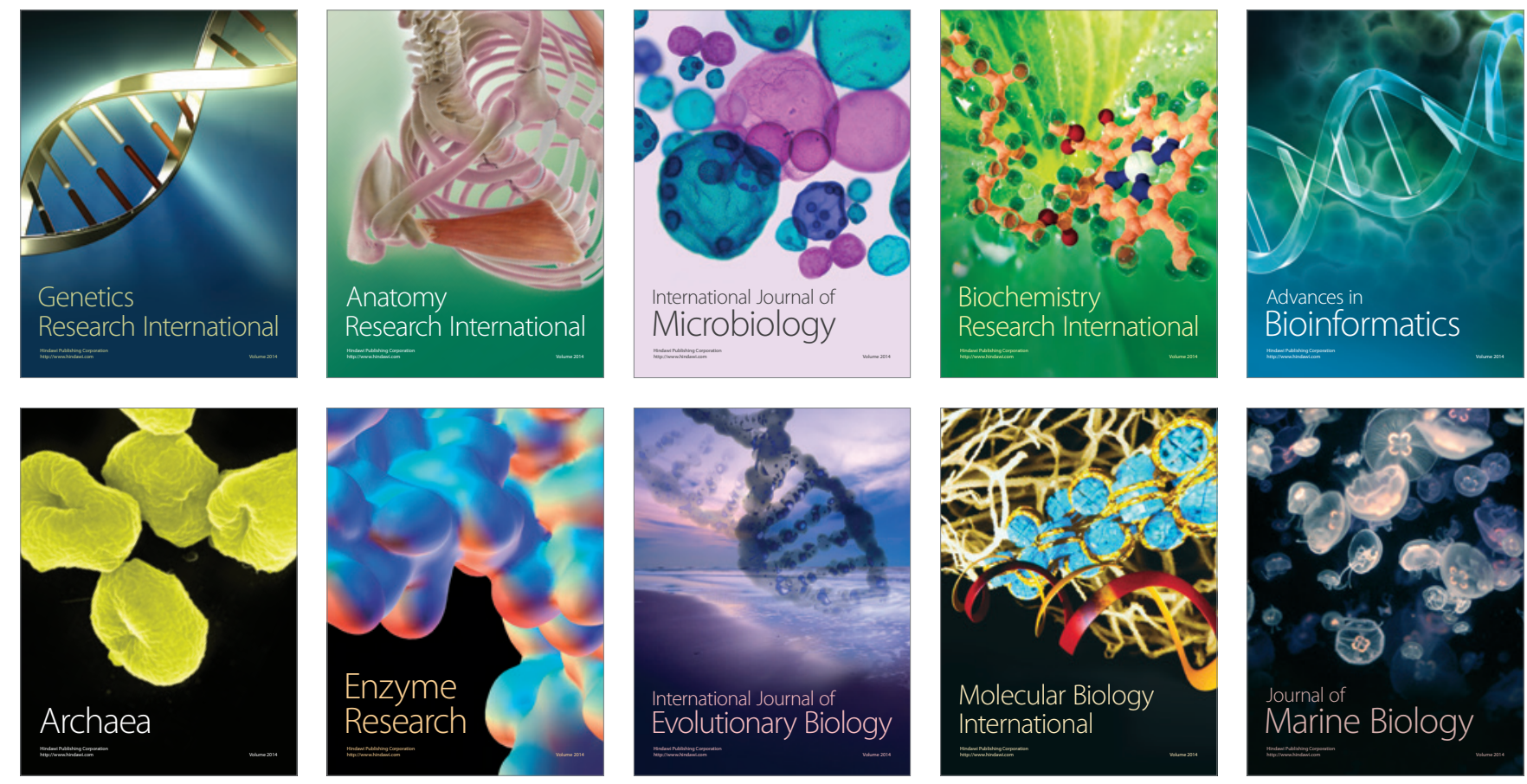